\title{
O QUE SERIA UM SUJEITO POLÍTICO PARA ALAIN BADIOU?
}

What would be a Political Subject for Alain Badiou?

¿Qué sería un Sujeto Político para Alain Badiou?

Quel serait un Sujet Politique pour Alain Badiou?

10.5020/23590777.rs.v20iEsp2.e8813

\section{Oswaldo França Neto 9}

Professor do Programa de Pós-graduação em Psicanálise do Departamento de Psicologia da Universidade Federal de Minas Gerais (UFMG).

\section{Resumo}

Tendo como referência alguns textos fundamentais da obra de Alain Badiou, este artigo procura cernir o que seria, para o filósofo, um sujeito no campo da política. Para orientar a discussão, propõe, inicialmente, uma diferenciação provisória entre esquerda e direita, e, a seguir, procura estabelecer como poderíamos depreender de seus escritos a oposição entre política e Estado, entendendo que, em sua teoria, a política se desenvolve a partir do que se apresenta como excesso em relação ao organograma estatal. A partir desse contexto, e correlacionando os conceitos de acontecimento, corpo subjetivo e verdade, desenvolve uma concepção de como se agenciaria um sujeito político, desdobrando uma tipologia para ele. Ao final, esboça uma correlação dessa concepção de sujeito com o humanismo e o capitalismo contemporâneos.

Palavras-chave: sujeito; política; estado; verdade; acontecimento.

\section{Abstract}

Having as reference some fundamental texts of the work of Alain Badiou, this article seeks to understand what would be, for the philosopher, a subject in the field of politics. To guide the discussion, he initially proposes a provisional differentiation between left and right, then seeks to establish how we could understand the opposition between politics and the State in his writings, understanding that, in his theory, politics develops from what is presented as excess concerning the state organization chart. From this context, and correlating the concepts of event, subjective body, and truth, he develops a conception of how a political subject would act, unfolding a typology for him. In the end, it outlines a correlation of this concept of the subject with contemporary humanism and capitalism.

Keywords: subject; politics; state; truth; event.

\section{Resumen}

Teniendo como referencia algunos textos clave de la obra de Alain Badiou, este trabajo busca exponer lo que sería, para el filósofo, un sujeto en el campo de la política. Para orientar la discusión, se propone, inicialmente, una diferenciación provisional entre izquierda y derecha y, en seguida, buscar establecer cómo podríamos comprender en sus escritos la oposición entre política y Estado, comprendiendo que, en su teoría, la política se desarrolla a partir de lo que se presenta como exceso en relación al organograma estatal. A partir de este contexto y correlacionando los conceptos de acontecimiento, cuerpo subjetivo y verdad, desarrolla una concepción de cómo se gestionaría un sujeto político, revelando una tipología para él. Al final, se esboza una correlación de esta concepción de sujeto con el humanismo y el capitalismo contemporáneo.

Palabras clave: sujeto; politica; estado; verdad; acontecimiento. 


\section{Résumé}

Ayant pour référence quelques textes fondamentaux de l'œuvre d'Alain Badiou, cet article cherche à comprendre ce qui serait, pour le philosophe, un sujet dans le champ politique. Pour guider la discussion, il propose, d'abord, une différenciation provisoire entre gauche et droite et, puis, il cherche à établir comment on pourrait comprendre l'opposition entre politique et État lorsque, dans ses écrits, la politique se développe à partir de de ce qui est présenté comme un excès par rapport à l'organigramme de l'État. A partir de ce contexte, et en faisant des liens entre les concepts d'événement, de corps subjectif et de vérité, il développe une conception de la façon dont un sujet politique pourrait agir, en même temps qu'il met en ouvre une typologie pour lui. À la fin, il esquisse une corrélation de ce concept de sujet avec l'humanisme et le capitalisme contemporains.

Mots-clés : sujet ; politique ; état ; vérité ; événement.

Alain Badiou afirma que os três livros fundamentais que trazem a essência de seu pensamento são O ser e o evento (1996), Logiques des mondes: L'être et l'événement (2006) e L'immanence des vérités: L'être et l'événement (2018). No segundo, Logiques des mondes: L'être et l'événement (2006), ele desenvolve, na sua primeira parte, o que seria uma teoria formal do sujeito. Esse conceito, porém, só pode ser mais bem apreendido se levarmos em consideração temas desenvolvidos nos outros dois livros. Desse modo, pretendemos aqui rediscutir esse conceito, resgatando, para isso, alguns outros trabalhados nos outros livros citados e explorando suas consequências, especificamente para o campo da política, já que, para o filósofo, o sujeito seria pensável não apenas nela, mas também nos campos da ciência, da arte e do amor.

Trata-se, a concepção do que seria um sujeito na política, de tema amplo, que se estende por uma miríade de importantes autores clássicos e contemporâneos. Badiou é controverso e sua teoria, com certeza, merece ser contraposta a esses outros autores, incluindo o psicanalista Jacques Lacan, citado com frequência pelo filósofo em seus textos. Não será, contudo, objeto deste artigo aprofundar essa contraposição, deixando para textos posteriores essa discussão.

Segundo Badiou (2006), uma verdadeira onda de esquerda aconteceu ao redor do mundo nos anos 1960. Suas principais manifestações teriam sido a Revolução Cultural na China, a luta contra a guerra do Vietnã nos EUA e o Maio de 1968 na França. Após essa onda de esquerda, aos seus olhos, observou-se um brutal movimento reacionário, movimento respaldado por uma legião de filósofos que ficaram conhecidos por "novos filósofos" (Badiou, 2006, p. 63). Esses militavam contra os movimentos de esquerda com o argumento de que não estavam lutando especificamente contra as ideias da esquerda, mas contra o totalitarismo que elas inevitavelmente desembocariam. Essa, na verdade, foi a estratégia discursiva que, iniciando-se por volta dos anos 1930, foi se consolidando como pano de fundo na defesa da democracia capitalista ocidental em oposição ao insurgente bloco comunista. O que esse discurso fez foi deslocar a luta esquerda $\mathrm{x}$ direita (que Badiou está chamando de revolução x ordem imperialista), para uma suposta luta da ditadura (ou totalitarismo) contra a democracia. A esquerda foi colada ao totalitarismo, à ditadura, e toda vez que algum conflito poderia se caracterizar como sendo entre esquerda e direita, ele imediatamente passava a ser nomeado como sendo entre totalitarismo e democracia.

Mas, afinal, o que significa ser de esquerda ou de direita?

Para Deleuze (2018), na sua essência, independentemente da época ou contexto histórico, a diferença estaria no campo da perspectiva. O pensamento de esquerda começa na periferia, no que está mais longe, e caminha em direção centrípeta. O pensamento de direita segue a direção inversa. Ele parte da própria pessoa e se direciona para a periferia, ao que está mais longe.

Uma pessoa de esquerda pensa, primeiro, naqueles que estão na margem, ou para além dela, aproximando-se progressivamente, até chegar aos que estão mais próximos e, finalmente, a si mesma. Já uma pessoa de direita, ao contrário, pensa, inicialmente e acima de tudo, em si mesma. A seguir, vai se distanciando (sua família nuclear, os outros parentes, os vizinhos etc.), entendendo sempre como menos valorizado aquele que mais distante se encontra de si.

Para um pensador de esquerda, segundo Badiou (2006), poderíamos propor que a Verdade política, com "V" maiúsculo, aquela que se apresentaria como eterna por sobre (ou sob) todas as suas localizações ao longo da história, seria a máxima de que a submissão de um homem em relação a outro não é natural. O primeiro nome histórico signo dessa verdade, ou seja, o nome que fixa o primeiro sujeito concebido como sendo seu portador, teria sido o escravo Spartacus, que comandou, no século I a.C., no auge do Império Romano, a primeira sublevação de caráter abrangente reconhecida na história ${ }^{1}$. Esse

1 "Nenhuma dúvida que a revolta de Spartacus seja o acontecimento de onde procede para o mundo antigo, ao presente, uma máxima de emancipação (o escravo quer e pode decidir de ser livre de retornar a sua terra)" (tradução do autor) ["Nul doute que la révolte de Spartacus soit l'événement d'où procede pour le monde antique, au présent, une máxime d'émancipation (l'esclave veut et peut décider d'être libre de retourner chez lui)'] (Badiou, 2006, p. 72). 
nome teria se tornado referência, (re)atualizando-se ao longo do tempo em todos os momentos em que essa verdade se fez ou se faz apresentar ou se localiza.

A cada vez que ela se (re)apresenta, ela o faz em um contexto diferente, portanto submetida a organizações lógicas distintas, sustentada por um nome imanente ao mundo ao qual se apresenta. Mas, mesmo sendo carreada por outro nome, a verdade da qual ele seria a fixação é, no fundo, a reatualização da primeira vez em que, para nós, ela teria se fixado, naquela ocasião sob o nome próprio de Spartacus e da declaração universal que o eternizou: “A escravidão não é natural” (Badiou, 2006, p. 74).

\section{O Estado e a Política}

Em um mundo onde o Um, ou aquilo que se coloca como sendo a completude de toda a situação, se institui sob a forma do Estado, apresentando-se como o receptáculo, inclusive, de tudo aquilo que não se deixa discernir pelo próprio saber estatal, ele, o Estado, aos olhos de Badiou (1995), tem a existência pautada em sua própria preservação, ou o que significa o mesmo, na preservação dos interesses estabelecidos. No caso de nossa democracia capitalista ocidental, esses interesses seriam eminentemente aqueles do capital, identificado por todos sob o nome de mercado.

Quem nunca utilizou ou escutou como sendo natural a expressão "O mercado não gostou" ou "O mercado não aceita" para justificar toda e qualquer medida feita, no fundo, para restringir distribuição de renda ou recuperação de igualdade social? O termo "mercado" é invocado sempre que se quer preservar privilégios ou bloquear medidas sociais. Mas quem é esse mercado? Qual é seu endereço? É possível conversar ou mandar uma carta para ele? Qual é a medida de sua potência? Voltando àquele que se apresenta como a incorporação do Um, qual é a quantificação da potência do Estado, cuja distinção em relação ao mercado em alguns momentos não se mostra clara e, em outros, se revela explicitamente como submissão?

O mercado, na economia capitalista contemporânea, se operacionaliza como um excesso incomensurável em relação ao dia a dia dos cidadãos comuns. Não parece desproposital propor-se o Estado como sendo a face que se deixa apresentar desse excesso. O Estado da civilização contemporânea é a face estatizada do mercado. Ele é o que faz Um de todo o conjunto, naturalizando a hiância inquantificável que separa os indivíduos (o cidadão) daquilo que efetivamente os governa (o mercado). O Estado, em nossa democracia capitalista ocidental, propõe-se como sendo aquele que detém a potência e o controle desse excesso inapreensível.

Para Badiou (2006), um mundo que se organiza sob a égide de tal superpotência, no caso o Estado, é um mundo propício à existência de sítios políticos, em que um acontecimento contingente e inusitado viria a se apresentar como subversão radical de toda a situação ao trazer para a imanência esse excesso até então inalcançável. Um procedimento político de verdade, assim, se apresentaria agenciado por um sujeito, como desdobramento dos fugazes e imprevisíveis momentos em que o excesso se deixa localizar como algo imanente ao próprio campo da situação.

A verdadeira política, aquela em que o termo sujeito seria pertinente, se processa assim sempre de forma imanente ao campo, em oposição ao Estado e sua inatingível transcendência. Fazendo uso de uma discussão levantada por Lacan no Seminário 19 (Lacan, 2012), poderíamos propor que a verdadeira política se apresenta como há Um, em oposição ao Um $e ́$ do Estado. No há Um, o Um se faz pensar como possibilidade a ser construída, a partir da imanência, desautorizando a superpotência estatal enquanto corporificação de um excesso proposto por ela como transcendente e inexpugnável. O há $U m$, ao retirar o Um da atualidade, deslocando-o para o registro da produção, possibilita a operacionalização do excesso no próprio campo do que se apresenta.

O excesso, assim, no caso da política, se materializa na diferença irredutível que existe entre o Um transcendente do Estado e tudo aquilo que se apresenta como elemento daquela situação. Um sujeito político se produz de forma imanente como sustentação de uma afirmação que se desdobra a partir do traço que resta de um acontecimento, carreando essa possibilidade da localização ou imanentização do excesso, eliminando o hiato intransponível que o submetia à potência estatal.

Teríamos que tentar cernir, agora, para Alain Badiou, o que seria esse acontecimento e o corpo que a partir dele se constitui.

\section{Acontecimento e Corpo Subjetivo}

Se a função do Estado ou a justificativa para sua existência, partindo da premissa de que ele é aquilo que se institucionaliza como transcendente à pura apresentação, é a tentativa de salvaguardar a situação contra o incontrolável ou indiscernível, um acontecimento político seria a apresentação contingente e inusitada de algo que viabilizasse uma fixação imanente desse excesso indiscernível, possibilitando uma espécie de ponte entre os dois níveis, a apresentação e a representação (Estado), eliminando a transcendência do segundo sobre o primeiro. $\mathrm{O}$ acontecimento deixa como traço "uma medida fixa da potência do Estado, uma parada (para o pensamento) da errância dessa potência" (Badiou, 2006, p. 78). Ele deixa uma marca imanente de um excesso, antes impalpável, por estar concebido como uma sobrepotência inatingível.

Em oposição ao Estado, que se propala, em sua transcendência, como portador inacessível desse excesso sem medida, um acontecimento político é aquele que imanentiza o excesso, dando a ele algum tipo de medida por meio de sua fixação 
a um traço (por exemplo, a frase que eternizou o que Spartacus representava: "Nós, escravos, queremos e podemos, como todo mundo, voltar para nossa terra"). Esse traço vai se tornar a medida do excesso, sua localização, implicando a possibilidade de inauguração de um novo mundo, antes impensável. Um acontecimento, nesses termos, nada mais é do que a imanentização do excesso, que se dá por meio do estabelecimento de uma medida fixa, localizada, deste. Algo inapreensível e, portanto, incontrolável pelas ferramentas classificatórias da situação, e que, até então, existiria apenas como estando sob os auspícios de uma transcendência, passa a se apresentar localmente e, dessa forma, acessível aos próprios habitantes daquele universo. Fazendo uma correlação com a teoria de Lacan, de quem Badiou se diz leitor, poderíamos dizer que o que antes era fora passa a ser um fora-dentro.

Um "presente" (Badiou, 2006, p. 60), nesse sentido, seria o conjunto do aqui e agora do que se produz como efeito ou consequência do traço que resta do acontecimento. No caso da revolta de Spartacus, por exemplo, um escravo que foge e se lança nesse presente, não está simplesmente se juntando a um exército. Essa é apenas a parte empírica, objetiva, do que está ocorrendo. O presente que seu ato representa, em termos subjetivos (e o presente é sempre uma subjetividade), é a colocação em cena, aqui e agora, de uma verdade que anteriormente sequer era pensável.

Esse novo presente, construído ponto a ponto a partir de um traço que resta de um acontecimento, se apresenta como um novo corpo. Os elementos desse corpo, assim como a parte indiscernível que the conferiria sua unificação num futuro a ser trilhado, pertencem àquele mundo. Mas, apesar de imanente ao mundo em questão, constitui-se como distinto do que se apresentava como hegemônico, lançando-se a um para-além dos limites que cerniam o universo aonde vem a aparecer.

Mas o que seria esse corpo agenciado por um sujeito (que poderíamos designar por político)? Trata-se de algo distinto do que normalmente se concebe como corpos naturais ou corpos objetivos, que existiriam em uma natureza objetiva. Se quisermos entender o que é um sujeito, torna-se necessário apreender o que seria a materialidade do corpo do qual ele seria o agente, seja produzindo-o (sujeito fiel), seja negando-o enquanto presente em produção (sujeito reativo), seja ocultando-o enquanto presente (sujeito obscuro). Vamos seguir os passos que Badiou se propõe a fazer e deixemos para mais adiante essa tipologia dos sujeitos aqui elencada.

Comecemos por uma definição preliminar do que seria um corpo: "ele é, no aparecer, o que porta e exibe o formalismo subjetivo" (Badiou, 2006, p. 76), ou seja, um corpo é, no campo da existência, o que porta o sujeito. Indo além, poderíamos dizer que um sujeito é o que produz, constitui ou sustenta um corpo.

Em O ser e o evento (Badiou, 1996), referenciado na teoria matemática dos conjuntos, o filósofo francês propõe que um corpo, como tudo o que existe, é múltiplo, ou multiplicidade. Mas o que concederia a essa multiplicidade o estatuto de se apresentar no mundo como uma unidade? Unidade essa, importante dizer, inacabada, já que todo corpo subjetivo - e, para Badiou, todo e qualquer corpo é subjetivo, enquanto portador de uma verdade -, apresenta, inexoravelmente, uma parte indiscernível, portanto carente de elucidação. Apesar de ser concebido, idealmente, como um objeto, ao operacionalizar-se enquanto corpo subjetivo, a infinitude que lhe é imanente o interdita de se fechar como tal.

Um corpo subjetivo não se determina, assim, por uma unificação objetivamente dada. Ele se pauta por uma afirmação que se projeta, não referenciada em identidades fechadas. Portanto, não se trata de uma afirmação que se rebata sobre si mesma, apresentando-se como objeto ou como algo idêntico a si, trata-se de uma afirmação que se apresenta como lançamento, que parte de uma clivagem a ser superada, e não suturada por uma identidade. Trata-se de uma afirmação causada não por um objeto natural, mas por um acontecimento, ou pela localização paradoxal de algo que, por definição, não é localizável.

\section{Todo Corpo Subjetivo é Clivado}

Enquanto lançamento ou produção, todo corpo, para ser efetivo, é obrigado a tratar certos pontos que se apresentam como obstáculos ao seu movimento, o que o força a se subdividir em partes, constituindo órgãos especializados no tratamento desses pontos, órgãos que podem ter maior ou menor eficácia. Mas do que se trata, a rigor, um ponto?

Pontos são lugares de decisão, em que a não escolha entre duas possibilidades mutualmente excludentes implicam em uma paralisia. Trata-se da imposição de um indecidível, em que a situação, por si só, não se mostra capaz de invalidar nenhuma das duas opções contraditórias. Para que continuemos, temos que decidir, sim ou não, sem possibilidade de gradações:

Um ponto do mundo (...) é a comparação da totalidade infinita do mundo (da totalidade dos graus) frente à instância da decisão, ou seja, a dualidade do 'sim' e do 'não'. 'Sustentar um ponto' quer dizer: sustentar essa instância frente ao mundo. Ou ainda: ter os meios subjetivos, ou seja, corporais e formais de submeter a situação à pressão decisional do Dois (eu digo 'sim' ou eu digo 'não', eu acho e declaro um ponto da situação). (Badiou, 2006, p. 614)

Há mundos que não têm ponto algum, o que seria outra forma de dizer se tratar de mundos onde não existem sujeitos. Seriam, nesse caso, mundos átonos, nos quais o afeto dominante é a depressão. Poderíamos propor ser essa a realidade do 
materialismo democrático contemporâneo, em que a verdade e, consequentemente, o sujeito, teriam sido levados à inexistência. As variadas formas de depressão e os quadros de ansiedade seriam, aqui, o seu corolário afetivo pregnante.

Mas a necessidade de especializações para o tratamento de pontos tem consequências não negligenciáveis. Ela determina uma clivagem no corpo entre os pontos, que têm necessidades e particularidades específicas, e o traço que o determina de uma forma genérica ou global. Essas especializações implicam, quase que invariavelmente, na produção de contradições.

Vamos tentar dar um exemplo contemporâneo, brasileiro. Peguemos o Partido dos Trabalhadores (PT). Este, partido de massas, de esquerda, para produzir uma mudança real no que considerava como sendo uma desigualdade social brutal dentro da sociedade brasileira, em um dado momento, considerou ser necessário apresentar-se no meio democrático como uma força viável de poder. Mas para ganhar as eleições e, principalmente, para viabilizar o exercício do poder após a vitória, mostrou-se necessário tratar pontos essenciais. Um deles, dos mais importantes, era o Congresso. Mas como lidar com um Congresso estruturado de uma forma eminentemente patrimonialista e oligárquica? Para trabalhar esse ponto, o PT se viu obrigado a entrar no jogo e a se instrumentalizar de forma a poder viabilizar as propostas que ele via como fundamentais de serem implantadas. A partir daí, nós vemos o mensalão, o caixa dois das campanhas, a distribuição de cargos etc.

O que se constituiu aí, com todas as suas consequências, foi um corpo cindido. O PT, partido de esquerda, dividido entre uma parte obrigada a tratar de forma mercantilista, pragmática, um ponto fundamental, que era um Congresso viciado e corrupto, e uma outra parte, sua imensa maioria, visceralmente contrária a esse tipo de prática.

Vemos, assim, que todo corpo subjetivo é genuinamente contraditório, cindido entre o traço que o determina na gênese e o mesmo traço quando no tratamento dos pontos locais, necessários à viabilização de sua eficácia enquanto corpo. Um corpo subjetivado é a impossível conjunção do Dois e do Um. Se ele aponta para, ou se apresenta, como Um, essa unidade só se afirma às custas da ultrapassagem do Dois irredutível que, enquanto processo em construção, ele é.

\section{Uma Tipologia para o Sujeito}

Voltemos agora à proposta de Badiou (2006) sobre uma tipologia dos sujeitos. Em termos formais, poderíamos começar afirmando que um sujeito existe sempre em relação a um presente, ou seja, em ato na operação que engendra ou produz um presente. É a forma de se posicionar frente a esse presente ou frente à novidade que, sustentada em suas consequências, subverte e transforma em passado a situação da qual se sobressai, que define a figura do sujeito em questão.

De acordo com a proposta de Badiou, existiriam, similarmente à tipologia proposta por Lacan a partir de sua leitura do texto freudiano, três tipos de sujeito. Lacan trabalha o sujeito levando em consideração as estruturas clínicas teorizadas por Freud - psicose, neurose e perversão -, sendo que, em cada uma dessas, de acordo com a forma de negação colocada em ação (Verwerfung, Verdrängung e Verleugnung), o sujeito se agenciaria de forma distinta (Chaves, 2018). Trabalhando também de uma forma tripartite, agenciados de forma similar a partir das negações colocadas em jogo, Badiou propõe que cada sujeito, a sua maneira, seria contemporâneo ao presente desencadeado pelo acontecimento, sem necessariamente nele se incorporar. Seriam, os três tipos de sujeito, o sujeito fiel, o sujeito reativo e o sujeito obscuro.

O primeiro, sujeito fiel, se caracterizaria pela implicação na produção do presente, ao qual ele se fideliza. O segundo, sujeito reativo, apesar de ser um dos beneficiários direto do que o presente propõe, acovarda-se frente aos riscos envolvidos na sua sustentação, recuando e passando a se movimentar no sentido de enfraquecê-lo, esmaecendo a potência que o impulsiona. Já o sujeito obscuro, antigo privilegiado da situação que o presente está transformando em passado, visa a todo custo resgatar o que perdeu, implicando-se não no esmaecimento do presente (como propõe o sujeito reativo), mas na destruição de seus elementos constitutivos e de tudo o que ele representa.

Todo o processo é, dessa forma, desencadeado por um sujeito fiel (a uma afirmação), mas assim que ele se coloca, sujeitos reativos e obscuros (formas distintas de negação dessa afirmação) logo entram em cena, ao mesmo tempo rivais e cúmplices, visando enfraquecer o presente sustentado pelo sujeito fiel (caso do sujeito reativo) ou ocultar o aparecer desse presente (caso do sujeito obscuro).

O sujeito fiel, assim, "nada mais é do que a ativação do presente da verdade concernida" (Badiou, 2006, p. 81). No que se refere à sua forma de funcionamento, poderíamos dizer que, em termos gerais, após o acontecimento, duas modalidades de sujeito fiel se fazem presentes no mundo. O primeiro se desdobra a partir da lógica do mundo antigo, em uma negociação infinita entre o antigo e o novo, tentando fazer com que o velho se possibilite abrir, passo a passo, à novidade que se fez apresentar. A segunda modalidade de sujeito fiel se apresenta nos momentos de decisão, em que a negociação se mostra impotente em possibilitar a abertura para a novidade. Trata-se, em geral, daqueles momentos em que, para que o novo continue a se produzir como presente, é necessária uma ruptura nos limites estabelecidos como possíveis pela situação antiga que resiste. Seriam os momentos em que se coloca uma escolha global, em que o sim e o não vão distinguir duas situações radicalmente distintas, sendo que uma delas, aquela defendida pelo sujeito fiel, implica em uma ampliação global em relação aos limites que cerniam a outra. 
Poderíamos pensar aqui na banda de Moebius, tão utilizada por Lacan (1998b). Trata-se de uma fita na qual fazemos uma semitorção e, a seguir, colamos suas extremidades, produzindo, dessa forma, uma superfície unilátera. Quando estamos pontualmente sobre um dos lados, para alcançarmos a face reversa, ou fazemos isso caminhando ao longo da banda, ou a perfuramos atravessando diretamente para o lado oposto. No caso da primeira opção, caminhando ao longo da fita, ao compararmos as duas extremidades que se colocariam como opostas e em posição invertida, qual teria sido o momento em que a ruptura qualitativa entre as duas teria ocorrido? Esse ponto, claro quando perfuramos a fita, fica esmaecido quando a transformação se processa no contínuo do deslocamento.

Guimarães Rosa (2001) escreveu um interessante conto, intitulado Meu tio o Iauaretê, em que a colmatação da hiância que o funcionamento moebiano operacionaliza pode também ser vislumbrado. Somos apresentados a um caçador de onças convocado a "desonçar" uma determinada região. Durante a missão, porém, ele vai progressivamente transformando-se no objeto que está caçando, até converter-se, ele próprio, em uma onça. Poderíamos nos perguntar, nesse processo de transformação em que o onceiro vira onça, onde se encontraria o ponto a partir do qual poderíamos afirmar que antes ele era humano e, a partir de então, seria onça.

De forma similar ao contínuo da banda de Moebius, as transformações vão se processando passo a passo, esmaecendo-se o ponto onde uma ruptura qualitativa teria ocorrido. Já na passagem direta da face à contraface nos confrontamos com uma mudança radical, consolidando-se a travessia como sendo o ponto onde uma escolha teve que ser enunciada e assumida de forma definitiva, onde a decisão se reduziu ao sim e ao não. De forma similar, podemos dizer que, no movimento de um corpo subjetivo, no qual um presente se constitui, há momentos em que é a negociação que agencia a transformação e há outros em que o confronto com um ponto se impõe, exigindo, para que o processo de uma verdade persevere, a decisão de um indecidível.

Pensando nesses dois tipos de sujeitos fiéis, Badiou (2006) lembra das considerações de Mao Tsé-Tung sobre o fato dele depositar sua confiança prioritariamente sobre os camponeses. Para ele, os burgueses que se posicionaram ao seu lado durante o desenrolar da revolução chinesa, por mais esclarecidos e convictos da causa que fossem, tenderiam a acompanhálo apenas até certo ponto. $\mathrm{Na}$ medida em que a mudança se aprofundasse em sua radicalidade, implicando em perdas reais de privilégios, ou exigindo confrontos que colocassem em risco sua integridade física, eles retrocederiam. Apenas nos camponeses, na medida em que para eles se trata, verdadeiramente, de tudo ou nada, Mao considerava que poderia confiar, pois permaneceriam até o final, inclusive, e especialmente, naqueles momentos em que a negociação se esgota, persistindo como único caminho possível aquele do confronto explícito, em que ou se rompe os limites que enrijecem a estrutura que se deseja ultrapassar ou se abre mão da novidade que o presente carreia.

Em consonância com Mao, poderíamos ensejar que um sujeito confrontado a transpor pontos é bem mais sólido em suas consequências do que aquele engajado unicamente na construção sequencial dos momentos de abertura. Isso ocorre porque, na decisão radical, nos defrontamos com uma mudança que vai implicar, sem retorno, todos os passos que vierem a seguir. A partir de então, toda a situação passará a estar concernida e passará a fazer parte do movimento de transformação.

Já no segundo caso, em que o processo se reduz aos momentos de abertura, em que decisões absolutas não têm que ser efetivadas, trata-se de uma transformação menos exigente, pois ela não enfrenta a mudança radical com todas as consequências que globalmente implicaria. Ela avança de forma menos consistente, negociando sua verdade e recuando quando a resistência se torna forte demais. Ela oscila, assim pasteurizando, quando se torna necessário, sua potência em romper os limites de uma real transformação que venha a implicar toda a situação.

Vejamos, agora, o segundo tipo de sujeito, o reativo.

No campo da política, o termo mais apropriado para o sujeito reativo seria reacionário (Badiou, 2006), já que ele se daria em reação ao presente igualitário e sem privilégios proposto pelo sujeito fiel, movido pelo medo das possíveis consequências que teria que enfrentar se viesse a se engajar nesse presente. Trata-se, nele, de um movimento conservador, em oposição às novas condições trazidas por essa subversão do estabelecido, mesmo que essa novidade lhe seja favorável por implicar no resgate das condições de vida que, em algum momento, lhe foram usurpadas. Mas mesmo sendo conservador, ele não deixa de ser marcado pela novidade do presente, levando-o a se operacionalizar como "não ao acontecimento", ou, dizendo de forma mais rigorosa, "como negação de seu traço" (Badiou, 2006, p. 63). Dessa forma, assim como a afirmação é uma novidade, a reação a ela também o será, por ser uma produção reativa específica a essa novidade (ou a essa verdade).

O sujeito reativo, assim, não se reduz a uma negação pura e simples. Ele não pode simplesmente propor a conservação literal do passado, mas deve afirmar alguma novidade para se apresentar, ele mesmo, como presente. Ele deve produzir uma resposta a aquilo que se apresenta como presente, oferecendo no lugar outro que seria mais razoável, mais pragmático, do que aquele proposto pelo sujeito fiel: “(...) e isso seria por que ele [o presente do sujeito reativo] resistiu à tentação catastrófica da qual o sujeito reativo declara que está contida no acontecimento" (Badiou, 2006, p. 64).

Podemos aqui utilizar o mesmo exemplo proposto por Badiou (2006), que foi a revolta de escravos capitaneada por Spartacus na Roma antiga. A partir do acontecimento Spartacus, para quem a liberdade e o retorno ao lar se apresentaram como possibilidade, não era suficiente para os escravos, temerosos de enfrentar os riscos da revolta, sustentarem-se 
subjetivamente com o assentimento puro e simples de retorno aos grilhões da situação antiga. Era necessário neles firmar-se a convicção de que esse presente novo, da forma como estava colocado, só teria por futuro a catástrofe (por exemplo, ele é impossível de ser conseguido, ele propõe um caos insustentável, todos que o seguirem vão morrer etc.), propondo no lugar um outro presente, um "presente apagado", (Badiou, 2006, p. 54), mas com a vantagem de ser o possível e melhor do que era o passado (os escravos que permanecessem seriam valorizados, adquiririam uma possibilidade maior de comprarem sua liberdade pelos meios estabelecidos etc.).

O sujeito reativo propõe extinguir o acontecimento por meio da negação do traço que resta dele, asseverando que o presente possível seria aquele sem novidade, reduzido a uma continuidade melhorada do passado. Se o sujeito fiel tem suas ações impulsionadas por uma afirmação, o sujeito reativo tem suas ações determinadas por uma negação. O que o move, ou o que o coloca em movimento, é o medo (do incerto, de morrer, de ser preso e torturado pelas forças estabelecidas etc.).

Para um sujeito reativo, a afirmação que o sujeito fiel sustenta tem por fim apenas a catástrofe ou o caos, e ele, então, recua, sustentando-se no discurso da razoabilidade, da sensatez, do pragmatismo, da defesa contra o incontrolável e a inconsistência. Seu objetivo, assim, não é acabar com o presente, mas torná-lo moderado, enfraquecido, uma mudança sem real mudança, ou a pequena mudança que é possível sem correr o risco das perigosas consequências que poderiam advir em decorrência da fidelidade à verdadeira mudança.

Por fim, temos aquele que Badiou nomeia por sujeito obscuro. Se o sujeito reativo se trata daquele que é solidário ao sujeito fiel em sua posição de explorado, mas não tem a coragem de enfrentar os riscos que o presente acarreta, o sujeito obscuro trata-se daquele que, no lugar do explorador da situação antiga, busca aniquilar ou levar à inexistência aquele presente que ameaça sua privilegiada situação.

Voltando ao exemplo de Spartacus, ele seria agora não o escravo medroso, ou seja, aquele que deveria participar como agente do novo presente, mas que recua frente aos seus riscos. Ele seria agora dos privilegiados da situação antiga, aqueles aos quais o presente decididamente é desfavorável por colocar em questão, e em perigo, os privilégios que lhes eram naturalizados. O que o sujeito obscuro operacionaliza não é o presente (produção do sujeito fiel), nem um presente apagado ou fraco (produção do sujeito reativo), mas a condução à inexistência da possibilidade de qualquer tipo de presente e a tentativa de um resgate absoluto do antigo, por meio de uma defesa intransigente da legalidade em geral.

Sua ação, porém, de forma similar ao sujeito reativo, não se sustenta com a defesa de um retorno puro e simples ao passado, mesmo que esse seja seu intento. Essa noite que eles desejam conservar/resgatar não se encontra mais dada em si, já que ela tem que ser novamente produzida em um mundo agora diferente, posto que marcado pelo acontecimento e pelo corpo consequência deste. O sujeito obscuro operacionaliza-se na tentativa de levar ao aniquilamento qualquer possibilidade de produção do novo, ou seja, qualquer possibilidade que não seja o passado, mesmo se esse passado tiver que se apresentar de forma diferente do que era, efetivamente: "Vemos como é aqui organizado o paradoxo de uma ocultação ela mesma ao presente" (Badiou, 2006, p. 69).

Como exemplo contemporâneo do sujeito obscuro político, Badiou (2006) cita os movimentos radicais extremistas que vicejam no mundo árabe. Para o filósofo francês, é infrutífero tentar entender "o islamismo político contemporâneo, $e$ singularmente suas variações ultra-reacionárias" (Badiou, 2006, p. 67), tendo como parâmetro apenas o funcionamento das antigas sociedades islâmicas antes da intervenção ocidental em busca do petróleo. Esse islamismo político e suas variações ultrarreacionárias atuais devem ser esclarecidos levando-se em consideração o presente que se apresenta hoje ao povo Islã, sem reduzi-lo, seja a uma resposta pura e simples à exploração e ao saque de seu petróleo pelo ocidente, seja a um suposto resgate de uma leitura mais precisa do Alcorão.

Para Badiou (2006), esse novo islamismo nada mais é do que uma tentativa de levar ao silêncio, ou à inexistência, as tentativas fragmentárias naquela região de se reinventar, no presente, a possibilidade de uma emancipação.

Um dos nomes desse presente que se quer apagar poderíamos propor como sendo a Primavera Árabe, que contorceu o mundo árabe alguns anos atrás. Ela está sendo levada ao esquecimento, e suas consequências apagadas, por meio da exaltação ao extremo de uma lei islâmica que se propõe eterna, mas que, a rigor, não se identifica naturalmente com a forma com que o islamismo era praticado anteriormente. Trata-se de um islamismo novo, de cara própria, que nada mais é do que a tentativa, sob o argumento de uma transcendência, de anular qualquer possibilidade do lançamento desse presente emancipatório e igualitário que se apresentou recentemente para o povo daquela região.

Sob esse aspecto, o islamismo político nada mais é do que um dos nomes do obscurantismo de hoje. Ele é correlativo aos sujeitos fiéis e aos sujeitos reativos ao presente emancipatório contemporâneo que fragmentariamente se faz presente hoje no mundo árabe.

\section{A Verdade como Localização da Verdade}

Outra discussão, então, se coloca. Se a história não se trata de uma linha evolutiva ou regressiva em relação a algo concebido como verdadeiro, mas consiste de escanções contingentes, o que entra em questão é a própria existência da verdade. Esta, 
em princípio, é necessariamente atemporal e eterna, ou seja, ela não pode ser interesseira, responsiva a questões identitárias restritas a uma ou algumas situações específicas (Badiou, 2018). A verdade de um dado mundo não poderia ser nem contingente, nem historicizável (França, 2014), isto é, ela não poderia ser entendida como possível de não concebível na essência daquele mundo desde sua origem. A verdade de um dado universo, por definição, é atemporal e eterna durante toda a sua existência.

Para que a não historicidade da verdade se preserve, o sujeito fiel, apesar de primeiro na sequência temporal, deve remeter, mesmo que hipoteticamente, a algo anterior, originário. Ele teria que, para existir, remeter a uma hipotética verdade já anteriormente apresentada, que o precedesse e que fosse desde sempre existente, da qual ele seria apenas uma localização atual. Assim, o sujeito teria que se remeter a uma suposta anterioridade que servisse de referência para a verdade eterna da qual ele seria a localização contemporânea (França, 2018).

Lembra-nos aqui a temporalidade lógica, em oposição à temporalidade cronológica, que Lacan (1998a) leu na proposta do inconsciente formulada por Freud. O recalque propriamente dito só adquire sentido, ou só adquire o estatuto de fundação do aparelho psíquico, a partir da postulação de um recalque anterior, originário, o qual, apesar de ser uma postulação secundária ao recalque propriamente dito, é concebido, logicamente, como anterior a este. Nessa concepção temporal, o passado é percebido/produzido como tal a partir do presente, que o faz existir como uma necessidade lógica para que a verdade atual seja concebida como sempre tendo existido. Badiou (2006, p. 74), em consonância com essa concepção temporal lógica com a qual trabalha a psicanálise, propõe a utilização do conceito de "ressurreição".

A apreensão do presente como sendo a atualização localizada de uma verdade que, por definição, deveria estar desde sempre lá, ocorre, assim, pela concepção de que essa localização atual seria nada mais, nada menos, do que o resgate do que teria sido uma apresentação originária dessa verdade, concedendo a atual o caráter de ser uma ressurreição. No caso da política, por exemplo, o presente de não importa qual máxima igualitária pode ser entendido como sendo a reapresentação de uma mesma verdade universal, aquela agenciada por Spartacus, da qual o enunciado original teria sido: A escravidão não é natural. É essa reativação de um passado originário que concederia ao presente o caráter de ser a atualização de algo que seria eterno. Todo sujeito fiel a uma verdade é, assim, concebido como a reapresentação de um mítico sujeito fiel logicamente predecessor, recolocando em cena uma verdade que teria sido, naquele passado originário, provisoriamente condenada ao esquecimento.

A concepção de ressurreição é o que concede àquele acontecimento localizado e contingente o caráter de eterno, ou seja, de ser, apesar de se apresentar como uma novidade inusitada, a atualização de algo que sempre existiu e que é comum a todas as vezes em que se reapresenta, seja no passado, seja no porvir.

\section{Sujeito, Humanismo e Capitalismo}

Um formalismo subjetivo político é, assim, para Badiou (2006), carreado por um corpo que se constitui referido ao traço que resta de um acontecimento, sendo que esse traço nada mais é do que a fixação de uma medida para um excesso antes inquantificável, por ser concebido ou constituído como uma transcendência inatingível. Esse traço justifica-se por motivos próprios, sem necessidade de dar satisfações ao que, até então, se apresentava como um poder superior à apresentação imediata. A revolta dos escravos comandados por Spartacus, por exemplo, se fez existir de forma imanente e não submetida a, até então, inatingível superpotência estatal, sustentada pela frase: "Nós, escravos, queremos e podemos, como todo mundo, voltar para a nossa terra".

Mas mesmo apresentando-se no campo, um sujeito nada tem a ver com a finitude que nos define enquanto natureza animal ou objetiva. Para Slavoj Zizek (2008), o termo humano, contemporaneamente, na civilização ocidental, passou a significar aquilo que em nós é finito ou biológico. A Declaração Universal dos Direitos Humanos (Organização das Nações Unidas [ONU], 1948), por exemplo, referência princeps de nossa democracia, trata-se da garantia de nossa igualdade enquanto ser biológico ou mortal, tendo como parâmetro certas particularidades/objetividades que seriam utilizadas para definir o animal humano em relação aos outros animais. Ao se cercar na defesa de particularidades, ela consolida o lançamento ao inaudito, ou à inexistência, daquilo que seria a nossa verdade indiscernível. Ao objetivar o humano, de forma indireta, ela desloca para a marginalidade a verdade subjetiva que nos sustenta, lançando-a ao reino do inumano, ou do inaudito. Sem entrar na discussão sobre a que particularidades essa Declaração está a serviço, discussão sobre a qual Zizek (2008) se debruça longamente, elas nada têm a ver com o sujeito e sua verdade. O sujeito e a verdade a que ele está fidelizado referem-se àquilo que, em nós, é eterno, infinito. O que a Declaração dos Direitos do Homem busca preservar e a verdade de um sujeito remetem-se a coisas distintas, desdobrando-se como portadoras de determinações que não compartilham da mesma lógica.

Badiou (2006, p. 7) propõe, então, o que ele considera ser a definição filosófica do capitalismo: "o capitalismo é uma visão do mundo que considera que o ser humano é redutível a sua animalidade". O grande problema dessa weltanschauung (visão de mundo) não é que nela se naturalizem as explorações, as ilegalidades etc. O grande problema é que, para o capitalismo, a única coisa que conta são os interesses particulares, seja de indivíduos, seja de grupos. A noção de verdade não tem sentido, já que, por definição, é desinteresseira. A verdade é um processo que se desencadeia não a partir do ser e de 
seus interesses, mas de algo que acontece a ele. Desde Freud (1900/1972), aprendemos que o indivíduo, entidade autônoma, movido por necessidades, e o sujeito desejante do inconsciente são distintos, determinados por urgências não sobreponíveis. Para o capitalismo, por exemplo, o amor é algo perigoso, por tornar aqueles que o experimentam negligentes com relação aos interesses particulares. Devemos, então, proteger aqueles que estão "cegos" por essa verdade, a experiência amorosa, convencendo-os a assinarem contratos de união que resguardem legalmente os interesses privados de cada um.

O capitalismo, assim, não é simplesmente uma estrutura de organização da economia, como se propõe a sua ciência, mas trata-se, também, de uma visão da humanidade, uma concepção do que é o ser humano. É essa visão que deve ser discutida. Se a filosofia, para Badiou, se preocupa com a vida, e viver é estar sob a égide de verdades, a visão de humanidade do capitalismo deve ser colocada em questão.

\section{Referências}

Badiou, A. (1995). Política, partido, representação e sufrágio: A polêmica entre Alain Badiou e Ronald Rocha. Belo Horizonte: Projeto.

Badiou, A. (1996). O ser e o evento. Rio de Janeiro: Jorge Zahar.

Badiou, A. (2006). Logiques des mondes: L'être et l'événement. Paris: Seuil.

Badiou, A. (2018). L'immanence des vérités: L'être et l'événement. Domont, France: Fayard.

Chaves, M. E. (2018). Estruturas clínicas em psicanálise: Um recorte. Reverso, 40(76), 55-62.

Deleuze, G. (set. 2018). O que é ser de esquerda [Vídeo]. Link

França, O. Neto. (2014). Verdade e ideologia na psicanálise e no capitalismo. Ágora, 17(2), 177-191.

França, O. Neto. (2018). Verdade, acontecimento e sujeito. Psicologia Clínica, 30(2), 365-382.

Freud, S. (1972). A interpretação dos sonhos. In J. Strachey, Edição das Obras Completas de Sigmund Freud (vol. 4). Rio de Janeiro: Imago. (Originalmente publicado em 1900)

Guimarães Rosa, J. (2001). Meu tio o Iauaretê. In J. Guimarães Rosa, Estas Estórias (5a ed., pp. 17-43). Rio de Janeiro: Nova Fronteira.

Lacan, J. (1998a). O tempo lógico e a asserção de certeza antecipada. In J. Lacan, Escritos (pp. 197-213). Rio de Janeiro: Jorge Zahar.

Lacan, J. (1998b). De uma questão preliminar a todo tratamento possível da psicose. In J. Lacan, Escritos (pp. 537-590). Rio de Janeiro: Jorge Zahar.

Lacan, J. (2012). O seminário. Livro 19: ... ou pior (1971-1972). Rio de Janeiro: Jorge Zahar.

Organização das Nações Unidas. (1948). Declaração Universal dos Direitos Humanos [Assembléia Geral da ONU]. Paris: ONU. Link

Zizek, S. (2008). A visão em paralaxe. São Paulo: Boitempo. 


\section{Como citar:}

Neto, O. F. (2020). O que seria um Sujeito Político para Alain Badiou? Revista Subjetividades, 20(Esp 2. O Contemporâneo à Luz da Psicanálise), e8813. http://doi.org/10.5020/23590777.rs.v20iEsp2.e8813

\section{Endereço para correspondência}

Oswaldo França Neto

E-mail: oswaldofranca@yahoo.com

Recebido em: $26 / 12 / 2018$

Revisado em: 19/11/2019

Aceito em: 09/07/2020

Publicado online: $30 / 11 / 2020$ 